\title{
Fetal Acidosis
}

National Cancer Institute

\section{Source}

National Cancer Institute. Fetal Acidosis. NCI Thesaurus. Code C113151.

An abnormally high hydrogen ion concentration (umbilical arterial blood pH less than 7.00) in fetal blood or tissue. 